\title{
Investigation of Relationship between Voltage and Nondetection Zone of OUV/OUF of Local Islanding Detection Techniques
}

\author{
M. Yingram and S. Premrudeepreechacharn
}

\begin{abstract}
The objective of this paper is to investigate relationship between voltage and nondetection zone of OUV/OUF of local islanding detection techniques of distributed generation in electric power system network. This paper shows experimental results of inverter-based DG and synchronous-based DG with parallel RLC load that causes the most difficulty in detection. The experiments have shown that, case of inverter-based DG: variation of active power associated with variation of off-grid voltage at $V_{P C C}$, case of synchronous-based DG: variation of off-grid voltage at $V_{P C C}$ was not associate with variation of active power but variation of off-grid voltage at $V_{P C C}$ associated with variation of reactive power. Nondetection zone of OUV of synchronous-based DG are very possibility that $\Delta Q$ can more than -9.6 MVAR or $\Delta Q$ can less than 3.6 MVAR which they can affect the $V_{P C C}$ to outside of normal voltage range when islanding condition is happen.
\end{abstract}

Index Terms-Islanding detection, distributed generation, grid-connected.

\section{INTRODUCTION}

Distributed generation (DG) is the electricity generation at the distribution site. DG including photovoltaic (PV), fuel cell, wind turbine is growing larger and more complicated. Features of DG include secure of electricity supply to customers, liberalisation of the electricity market, reduced $\mathrm{CO}_{2}$ emission by the introduction of renewable energy sources, increased power availability and reliability, increased standby capacity, improved power quality, grid support, combined generation of heat and power, and cost saving of adding more remote generating sources [1]. However, the advent of DG makes some problems to the stability and the power quality in the adjacent utility. Specially, most issued problem is islanding phenomenon which it is a condition in which a portion of the utility system, which contains both load and generation, is isolated from the remainder of the utility system and continues to operate. Generally, islanding is undesirable because it can cause safety problems to utility service personnel or related equipment [2].

When electrical energy transfer to electric power system network by utility system is isolated, islanding condition is formed. Anti to this condition, control system of DG must

Manuscript received July 3, 2013; revised December 16, 2013. Authors would like to thank financial supports from the Energy Conservation Promotion Fund, Energy Policy and Planning Office, Ministry of Energy, Thailand and also Graduate School, Chiang Mai University.

The authors are with the Department of Electrical Engineering, Faculty of Engineering, Chiang Mai University, Chiang Mai, 50200 Thailand (e-mail: manopyin@hotmail.com,suttic@gmail.com). have detection of islanding condition According IEEE Std. 1547,2003 set the DG interconnection system shall detect the island and cease to energize the electric power systems network within two seconds of the formation of an island [3].

The DG connected to the power system is a growing trend [4]. To prevent islanding phenomenon, many anti-islanding methods have been studied until now. Islanding detection techniques can be divided into local and remote techniques. The local techniques can further be divided into passive, active and hybrid techniques. Remote islanding detection techniques: These detection techniques are based on some kind of communication between the grid and the DG. They are more reliable than the local techniques, but they are more expensive to implement. Local islanding detection techniques are based on the measurement of some parameters (voltage, current, frequency, among others on the distributed generator side. They are classified as passive, based exclusively on the monitoring of these parameters, and active techniques, which intentionally introduce disturbances at the output of the inverter and observe whether the parameters outlined above are affected. Hybrid methods employ both the active and passive detection techniques [5].

As, IEEE Std. 929, 2000 mentioned islanding condition, voltage will sudden variation when islanding condition is happen [2]. Comparison is measured voltage at PCC point $\left(V_{P C C}\right)$ if $V_{P C C}>110 \%$ or $V_{P C C}<88 \%$ shown that islanding condition occurs [6]. Usually Nondetection Zone (NDZ) of islanding detection techniques is difficult evaluation but some techniques have effort such phase jump [7], active frequency drift (AFD) [8] and Sandia frequency shift (SFS) [9]. Especially OUV/OUF of islanding detection techniques can evaluation of NDZ by Inverter-based DG and evaluation of NDZ by Synchronous Distributed Generator (SDG) [7], [10]. Furthermore, over/under voltage (OUV) of islanding detection technique has been used in inverters such grid-connected inverter of Sunnergy Technology Co., Ltd., Thailand. Moreover, local islanding detection techniques interested in research and develop because they are suitable in used with small DGs. As remote islanding detection techniques are more expensive than local islanding detection techniques [5].

Therefore, investigation of relationship between voltage and nondetection zone of OUV/OUF of local islanding detection techniques will help to be more understanding in islanding phenomenon. Researchers can use this knowledge to develop new local islanding detection technique or adjust old local islanding detection techniques for increase efficiency and decrease disadvantages. 


\section{ISLANDING CONDITION}

Islanding is a condition in which a portion of the utility system that contains both load and generation is isolated from the remainder of the utility system. Phenomena of islanding condition may occur several reasons such a result of a fault that is detected by the utility but is not detected by the DG, a result of an accidental opening of the normal utility supply by an equipment failure, a result of human error or malicious mischief, an act of nature, etc. Cause of islanding condition should be avoided because the utility cannot control voltage and frequency in the island which there is the possibility of damage to equipment because voltage or frequency excursions outside of the acceptable ranges which the utility has no control, may interfere with the restoration of normal service by the utility, may create a hazard for utility line-workers by causing a line to remain energized when it is assumed to be disconnected from all energy sources, Reclosing into an island may result in re-tripping the line or damaging the distributed resource equipment because of out-of-phase closure [2].

\section{NONDETECTION ZONE OF OUV/OUF}

"Non-detection zone" (NDZ) can be defined as the range in terms of the difference between the power supplied by the DG inverter and that consumed by the load, in which an islanding detection scheme under test fails to detect this condition [11].

\section{A. NDZ of OUV/OUF of Inverter-Based DG}

Zhihong Ye, Amol Kolwalkar, Yu Zhang, Pengwei Du, and Reigh Walling propose a nondetection zone (NDZ) of inverter-based DG as a performance index to evaluate different anti-islanding schemes. The NDZ for under/over voltage and under/over frequency are derived analytically and validated by PSCAD simulation [7], [12].

Over/under-voltage (OUV) and over/under-frequency (OUF) Techniques of over/under-voltage protection, OVP/UVP and over/under-frequency protection, OFP/UFP into passive islanding detection method, allow the detection of islanding phenomenon through the measure of voltage and/or frequency at the Point of Common Coupling (PCC), and subsequent comparison with the limits set for proper operation. If the measured values are outside the established range, the inverter is stopped or disconnected. Fig. 1 shows the DG System Configuration and Power Flows [11].

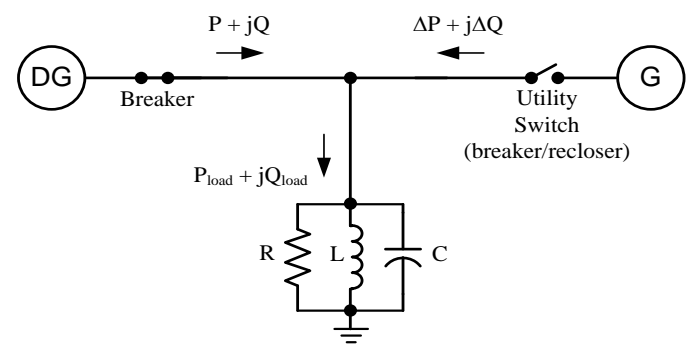

Fig. 1. DG system configuration and power flows.

It is usually assumed that the local load can be modeled as a parallel RLC circuit because for most islanding detection method (IDM) some type of RLC load that causes the most difficulty in detection. The equivalent circuit of grid connected DG power generation system is shown in Fig. 2 [7], [13], [14].

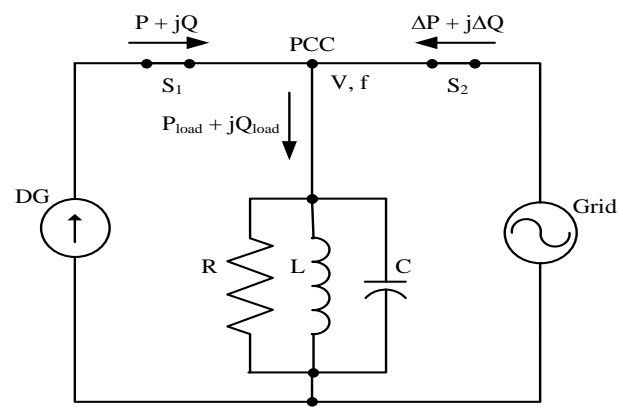

Fig. 2. Equivalent circuit of grid connected DG power generation system.

Power flows show in Fig. 2, node "PCC" or the PCC between the utility grid and DG system. The utility grid voltage source at the right can be disconnected from node "PCC" by the switch $\mathrm{S}_{2}$ (breaker/recloser). A local load is also connected at the PCC.

When the utility grid is connected (breaker is closed), the real and reactive power $P+j Q$ flows from the DG system to node "PCC", and $P_{\text {load }}+j Q_{\text {load }}$ flows from node "PCC" to the local load. The power flows from utility grid to node "PCC" are $\Delta P+j \Delta Q$. These power equations are shown in equation (1).

$$
\begin{aligned}
& P_{\text {load }}=P+\Delta P \\
& Q_{\text {load }}=Q+\Delta Q
\end{aligned}
$$

The amplitude and phase angle of RLC parallel load impedance, resonant frequency $f_{0}$, quality factor $Q_{f}$ are defined in equation (2).

$$
\begin{gathered}
|z|=\frac{1}{\sqrt{\frac{1}{R^{2}}+\left(\frac{1}{\omega L}-\omega C\right)^{2}}} \\
\phi_{\text {load }}=\tan ^{-1}\left[Q_{f}\left(\frac{f_{0}}{f}-\frac{f}{f_{0}}\right)\right] \\
f_{0}=\frac{1}{2 \pi \sqrt{L C}} \\
Q_{f}=R \sqrt{\frac{C}{L}}
\end{gathered}
$$

The Non-Detection Zone (NDZ) of reactive power is

$$
Q_{f}\left[1-\left(\frac{f}{f_{\min }}\right)^{2}\right] \leq \frac{\Delta Q}{P} \leq Q_{f}\left[1-\left(\frac{f}{f_{\max }}\right)^{2}\right]
$$

Select IEC Std. 62116 set (normal frequency in Thailand is $\left.f_{0}=50 \mathrm{~Hz}\right) f_{\max }=48.5 \mathrm{~Hz}, f_{\min }=51.5 \mathrm{~Hz}, Q_{f}=1$ replace equation (3) [6].

$$
-6.28 \% \leq \frac{\Delta Q}{P} \leq 5.74 \%
$$

The Non-Detection Zone (NDZ) of active power is

$$
\left(\frac{V}{V_{\max }}\right)^{2}-1 \leq \frac{\Delta P}{P} \leq\left(\frac{V}{V_{\min }}\right)^{2}-1
$$

Select IEC Std. 62116 set $V_{\max }=115 \%, V_{\min }=85 \%$ replace equation (4) [6]. 


$$
-24.39 \% \leq \frac{\Delta P}{P} \leq 38.41 \%
$$

Therefore, the NDZ of OUV and OUF are shown in Fig. 3.

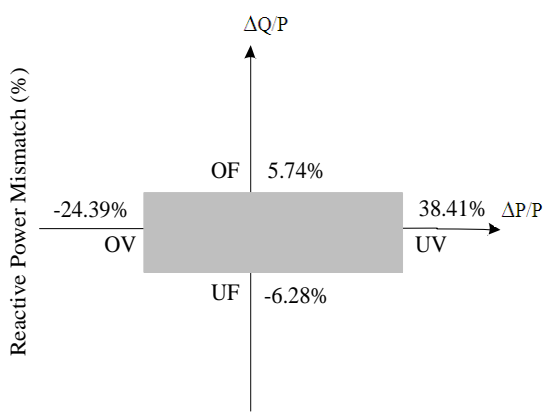

Active Power Mismatch $(\%)$

Fig. 3. Nondetection zone of OUV and OUF of inverter-based DG.

\section{B. NDZ of OUV/OUF of Synchronous Distributed Generator}

Jose C. M. Vieira, Walmir Freitas, Wilsun Xu, and Andre Morelato investigates these nondetection zones associated with the common anti-islanding protection schemes of synchronous distributed generators: frequency and voltage-based relays which nondetection zones were obtained through repeated dynamic simulations which the system employed is presented in Fig. 4 [10].

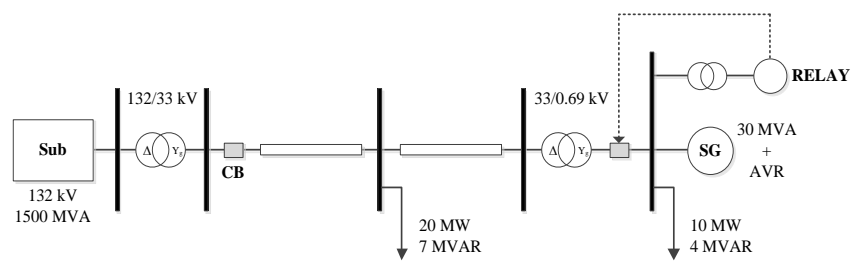

Fig. 4. Single line diagram of the test system.

In the system are two aspects of power imbalance in an island. One is the active power imbalance and the other is the reactive power imbalance. Any particular power imbalance situation in an island can therefore be presented as a point in the $\Delta P$ and $\Delta Q$ where $\Delta$ denotes power imbalance (a positive value denotes surplus power).

The resulting nondetection zone of the association of both relays is presented in Fig. 5. Therefore, the anti-islanding performance of this protection scheme is improved when compared to the individual action of the frequency and the voltage relay. The resulting nondetection zone is always the intersection of the nondetection zones of the associated devices.

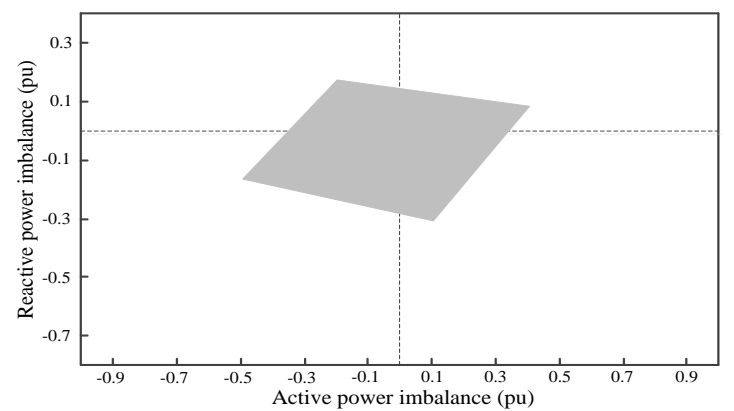

Fig. 5. NDZ of the association of a frequency and voltage relay, adjusted in $57.5 \mathrm{~Hz} / 62.5 \mathrm{~Hz}$ and $0.80 / 1.20$ p.u., respectively. Required time: $500 \mathrm{~ms}$; load type: constant impedance; exciter mode: reactive power control.
From the results, this paper conclude that the practical size of NDZ that should be used for DG interconnection studies is $\Delta P=[-0.3,0.113] \Delta Q=[-0.32,0.12]$ (this is a best estimate of the boundary of the slanted NDZ). All of these values are expressed in per unit quantities, where 1 p.u. $=30$ MVA.

\section{EXPERIMENTS AND RESULTS}

Experiment is the same as the anti-islanding testing diagram defined in UL 1741-1999, IEEE Std. 929-2000 and IEEE Std. 1547-2003 [2], [3], [7].

There is a specific definition for RLC load as a testing condition. The resonant frequency of the RLC load is the same as grid line frequency. Usually unity power factor condition combined with the RLC load, the worst case of islanding detection when the active power or the reactive power is $100 \%$ match between the load and the DG output [2], [7]. The experiment will build Islanding condition by off-grid (off switch) between the Point of Common Coupling (PCC) and Utility.

\section{A. Relationship between Voltage and Nondetection Zone of OUV/OUF of Inverter-Based DG}

Experiment to Investigate relationship between Voltage and nondetection zone of OUV/OUF by use inverter shown in Fig. 6 and Fig. 7.

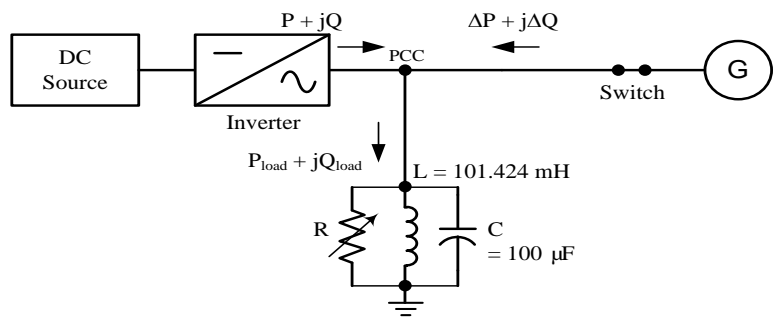

Fig. 6. Experimental circuit diagram by inverter-based DG.

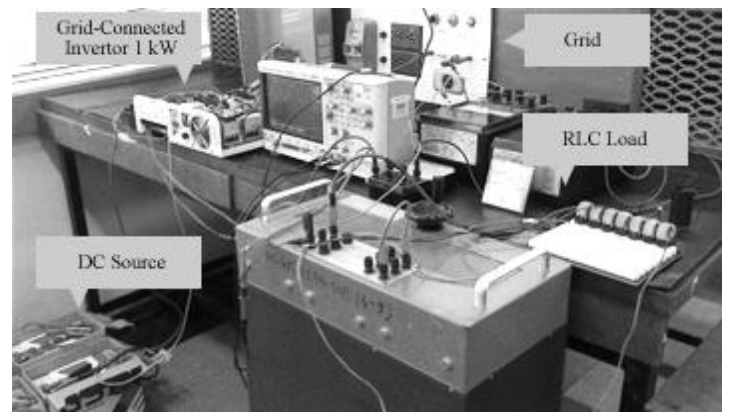

Fig. 7. Experiment in research and develop power electronic laboratory.

Form Fig. 6 experimental circuit diagram has:

$$
\begin{aligned}
& X_{L}=2 \pi f L=2 \pi(50)\left(101.424 \times 10^{-3}\right)=31.84 \mathrm{Ohm} \\
& X_{C}=\frac{1}{2 \pi f C}=\frac{1}{2 \pi(50)\left(100 \times 10^{-6}\right)}=31.84 \mathrm{Ohm}
\end{aligned}
$$

The load is resonant condition because $X_{L}=X_{C}$ and this resonant condition will make to $Q_{\text {load }}=0$.

In the experiment set active power of DG is $P=1 \mathrm{~kW}$, power factor of DG is $P F=1$, power factor of load is $P F_{\text {load }}=$ 1 and change active power of load from $600 \mathrm{~W}$ to $1,200 \mathrm{~W}$ (100 W per step). The worst case of islanding detection in the experiment when the active power of load is $1,000 \mathrm{~W}$ because active power of load as valuable as active power of DG. 
TABLE I: RELATIONSHIP BETWEEN VOLTAGE AND ACTIVE POWER OF INVERTER

\begin{tabular}{|c|c|c|c|c|c|c|c|}
\hline \multirow{3}{*}{$\begin{array}{c}P_{\text {load }} \\
\text { (W) }\end{array}$} & \multirow{3}{*}{$\begin{array}{c}P \\
(\mathbf{W})\end{array}$} & \multirow{3}{*}{$\begin{array}{c}\Delta P \\
(\mathbf{W})\end{array}$} & \multirow{3}{*}{$\begin{array}{c}\Delta P / P \\
(\%)\end{array}$} & \multirow{2}{*}{\multicolumn{3}{|c|}{ On Grid }} & \multirow{3}{*}{$\begin{array}{c}\begin{array}{c}\text { Off } \\
\text { Grid }\end{array} \\
V_{P C C} \\
(V)\end{array}$} \\
\hline & & & & & & & \\
\hline & & & & $\begin{array}{c}V_{P C C} \\
(V)\end{array}$ & $\begin{array}{l}V_{P C C^{*}} \\
115 \% \\
\end{array}$ & $\begin{array}{c}V_{P C C} * \\
85 \% \\
\end{array}$ & \\
\hline 600 & 1,000 & -400 & -40 & 230.2 & 264.7 & 195.7 & 253.2 \\
\hline 700 & 1,000 & -300 & -30 & 233.4 & 268.4 & 198.4 & 249.3 \\
\hline 800 & 1,000 & -200 & -20 & 231.6 & 266.3 & 196.9 & 240.5 \\
\hline 900 & 1,000 & -100 & -10 & 229.8 & 264.3 & 195.3 & 191.0 \\
\hline 1,000 & 1,000 & 0 & 0 & 229.8 & 264.3 & 195.3 & 175.0 \\
\hline 1,100 & 1,000 & 100 & 10 & 226.3 & 260.2 & 192.4 & 159.1 \\
\hline 1,200 & 1,000 & 200 & 20 & 229.8 & 264.3 & 195.3 & 148.5 \\
\hline
\end{tabular}

The experimental results include Table I shows relationship between voltage and active power and Fig. 8 shows some figure of the experimental results.

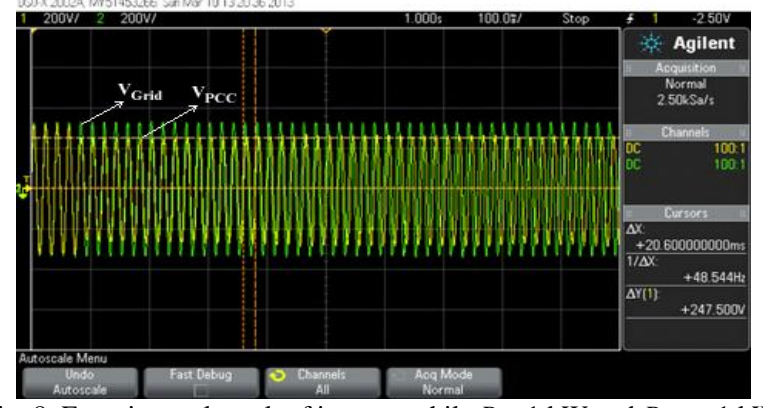

Fig. 8. Experimental result of inverter while $P=1 \mathrm{~kW}$ and $P_{\text {load }}=1 \mathrm{~kW}$.

\section{B. Relationship between Voltage and Nondetection Zone of OUV/OUF of Synchronous-Based DG}

Experiment to investigate relationship between voltage and nondetection zone of OUV/OUF by use synchronous distributed generator shown in Fig. 9 and Fig. 10.

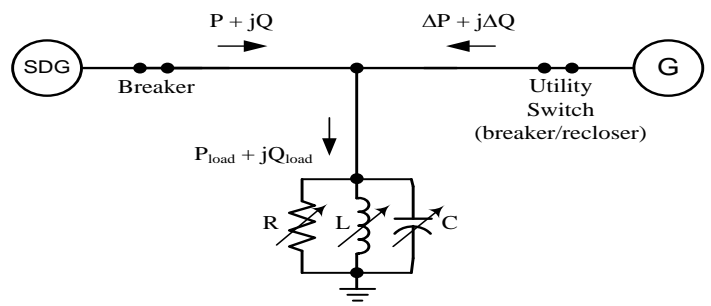

Fig. 9. Experimental circuit diagram by synchronous-based DG.

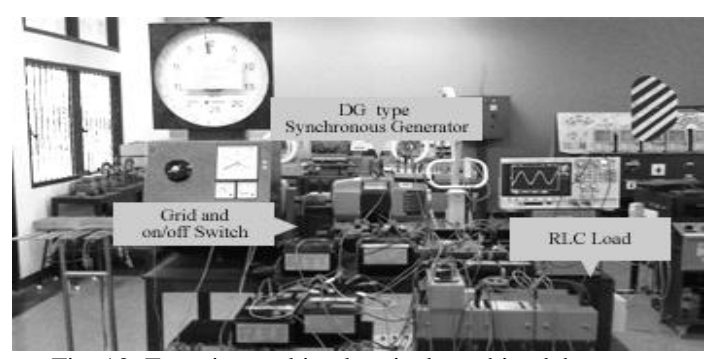

Fig. 10. Experimental in electrical machine laboratory.

Experiment in Table II set active power of load is $P_{\text {load }}=1$ $\mathrm{kW}$, power factor of load is $P F_{\text {load }}=1$, power factor of DG is $P F=1$ and change active power of DG type synchronous distributed generator from $100 \mathrm{~W}$ to $900 \mathrm{~W}$ (100 W per step). The worst case of islanding detection in the experimental when the active power of DG is $500 \mathrm{~W}$ because the active power is match between the DG and the load.

The experimental results include Table II shows relationship between voltage and active power and Fig. 11 shows some figure of the experimental results.

TABLE II: RELATIONSHIP BETWEEN VOLTAGE AND ACTIVE POWER OF

\begin{tabular}{|c|c|c|c|c|c|c|c|}
\hline \multicolumn{8}{|c|}{ SDG } \\
\hline \multirow{2}{*}{$\underset{(\mathbf{W})}{\boldsymbol{P}}$} & \multirow{2}{*}{$\begin{array}{c}\boldsymbol{P}_{\text {load }} \\
\text { (W) }\end{array}$} & \multirow{2}{*}{$\begin{array}{c}\Delta \boldsymbol{P} \\
(\mathbf{W})\end{array}$} & \multirow{2}{*}{$\begin{array}{c}\Delta P / P \\
(\%)\end{array}$} & \multicolumn{3}{|c|}{ On Grid } & \multirow{2}{*}{$\begin{array}{c}\text { Off } \\
\text { Grid } \\
V_{P C C} \\
(V)\end{array}$} \\
\hline & & & & $\begin{array}{c}V_{P C C} \\
(V)\end{array}$ & $\begin{array}{l}V_{P C C^{*}} \\
115 \%\end{array}$ & $\begin{array}{l}V_{P C C^{*}} \\
85 \%\end{array}$ & \\
\hline 100 & 500 & 400 & 400.0 & 126.6 & 145.6 & 107.6 & 131.5 \\
\hline 200 & 500 & 300 & 150.0 & 126.6 & 145.6 & 107.6 & 135.8 \\
\hline 300 & 500 & 200 & 66.7 & 126.6 & 145.6 & 107.6 & 122.3 \\
\hline 400 & 500 & 100 & 25.0 & 126.6 & 145.6 & 107.6 & 146.9 \\
\hline 500 & 500 & 0 & 0.0 & 126.2 & 145.1 & 107.3 & 122.7 \\
\hline 600 & 500 & -100 & -16.7 & 126.6 & 145.6 & 107.6 & 101.4 \\
\hline 700 & 500 & -200 & -28.6 & 126.6 & 145.6 & 107.6 & 106.2 \\
\hline 800 & 500 & -300 & -37.5 & 126.6 & 145.6 & 107.6 & 116.5 \\
\hline 900 & 500 & -400 & -44.4 & 126.6 & 145.6 & 107.6 & 134.5 \\
\hline
\end{tabular}

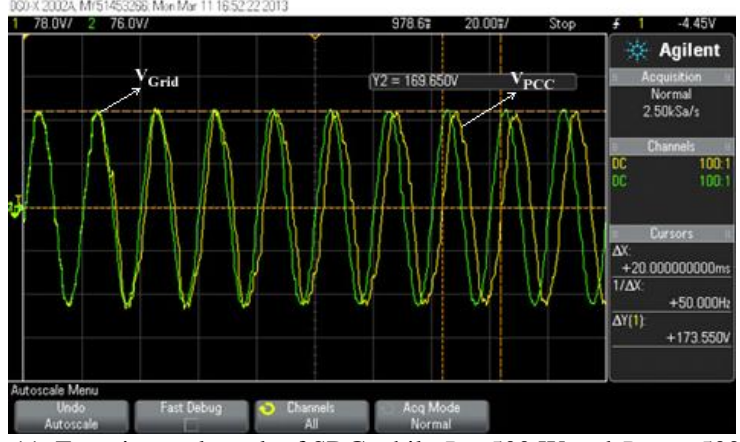

Fig. 11. Experimental result of SDG while $P=500 \mathrm{~W}$ and $P_{\text {load }}=500 \mathrm{~W}$.

Because of, synchronous distributed generator can vary even reactive power valuation which they help understand to relationship between of voltage and reactive power. Therefore, experiment in Table III set active power of load is $P_{\text {load }}=500 \mathrm{~W}$, power factor of load is $P F_{\text {load }}=0.894$ lag $\left(Q_{\text {load }}\right.$ $=250 \mathrm{VAR}$ ), active power of DG is $P=500 \mathrm{~W}$ and change power factor of DG type synchronous distributed generator from 0.8 leading to 0.96 leading ( 0.02 per step). The worst case of islanding detection in the experiment when the power factor of DG is 0.9 leading ( 242 VAR) because the reactive power is about match between the DG and the load.

The experimental results include Table III shows relationship between voltage and reactive power and Fig. 12 shows some figure of the experimental results.

TABLE III: RELATIONSHIP BETWEEN VOLTAGE AND REACTIVE POWER

\begin{tabular}{|c|c|c|c|c|c|c|c|}
\hline \multicolumn{8}{|c|}{ OF SDG } \\
\hline \multirow{2}{*}{$\begin{array}{c}\mathbf{Q} \\
\text { (Var) }\end{array}$} & \multirow{2}{*}{$\begin{array}{c}\text { Qload }_{\text {load }} \\
\text { (Var) }\end{array}$} & \multirow{2}{*}{$\begin{array}{c}\Delta \mathbf{Q} \\
(\text { Var) }\end{array}$} & \multirow{2}{*}{$\begin{array}{c}\Delta Q / P \\
(\%)\end{array}$} & \multicolumn{3}{|c|}{ On Grid } & \multirow{2}{*}{$\begin{array}{c}\begin{array}{c}\text { Off } \\
\text { Grid }\end{array} \\
V_{P C C} \\
(V)\end{array}$} \\
\hline & & & & $\begin{array}{c}V_{P C C} \\
(V)\end{array}$ & $\begin{array}{l}V_{P C C^{*}} \\
115 \%\end{array}$ & $\begin{array}{c}V_{P C C^{*}} \\
85 \%\end{array}$ & \\
\hline 375 & 250 & -125 & -25 & 124.5 & 143.2 & 105.8 & 115.3 \\
\hline 349 & 250 & -99 & -19.8 & 124.5 & 143.2 & 105.8 & 116.0 \\
\hline 323 & 250 & -73 & -14.6 & 124.5 & 143.2 & 105.8 & 116.0 \\
\hline 297 & 250 & -47 & -9.4 & 124.5 & 143.2 & 105.8 & 116.7 \\
\hline 270 & 250 & -20 & -4 & 124.5 & 143.2 & 105.8 & 125.9 \\
\hline 242 & 250 & 8 & 1.6 & 124.5 & 143.2 & 105.8 & 129.4 \\
\hline 213 & 250 & 37 & 7.4 & 124.5 & 143.2 & 105.8 & 133.0 \\
\hline 182 & 250 & 68 & 13.6 & 125.9 & 144.8 & 107.0 & 133.7 \\
\hline 146 & 250 & 104 & 20.8 & 124.5 & 143.2 & 105.8 & 135.1 \\
\hline
\end{tabular}




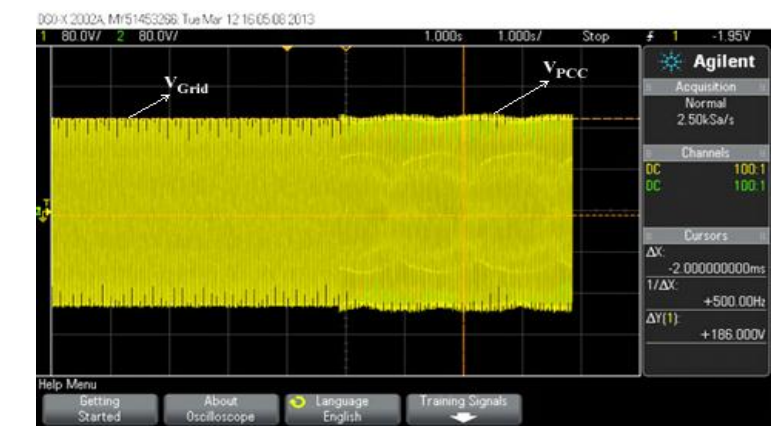

Fig. 12. Experimental result of SDG while $Q=146 \mathrm{VAR}$ and $Q_{\text {load }}=250$ VAR.

\section{ANALYSIS OF THE EXPERIMENTAL RESULTS}

\section{A. Relationship between Voltage and Active Power}

Analysis of the experimental results, relationship between voltage and active power can be divided 2 cases.

\section{1) Case of inverter-based $D G$}

Experimental results in Table I shows $V_{P C C}$ (voltage at the Point of Common Coupling), before and after islanding condition is happen which they are in column 5 (on-grid voltage) and column 8 (off-grid voltage). Observation, $V_{P C C}$ (column 8) decrease when $\Delta P$ (column 3) increase. The results accord with Fig. 3 nondetection zone of OUV and OUF of inverter-based DG, when $\triangle P / P$ increase from negative to positive which it will affect to off-grid voltage at $V_{P C C}$ decrease from Over Voltage $(\mathrm{OV})$ to Under Voltage (UV) when comparison with on-grid voltage at $V_{P C C}$ (on-grid voltage at $V_{P C C}$ is same as $\left.V_{\text {Grid }}\right)$. The results shown that a nondetection zone (NDZ) of OUV of inverter-based DG is true that it proposed by Zhihong Ye, Amol Kolwalkar, Yu Zhang, Pengwei Du, and Reigh Walling. Moreover. If inverter uses Over/Under Voltage (OUV) islanding detection technique for anti-islanding, consider in TABLE I shown that the inverter could detect islanding in row 4 to 7 because $V_{P C C}$ in column 8 (off-grid voltage) less than 0.85 multiply $V_{P C C}$ in column 5 (on-grid voltage). As, this paper selected IEC Std. 62116 set normal voltage range $85 \% \leq V \leq 115 \%$, if $V$ ( $V$ is same as off-grid voltage at $V_{P C C}$ ) more than $115 \%$ or less than $85 \%$ shown that islanding condition occurs and inverter control system must cease to energize the electric power systems network. If the inverter set over/under voltage as constant normal voltage of utility is $220 \mathrm{~V}$, over voltage $=253$ $\mathrm{V}$ and under voltage $=187 \mathrm{~V}$. Consider in Table I shown that the inverter could not detect islanding in row 2, 3 and 4 because $V_{P C C}$ (off-grid voltage) cannot more than $253 \mathrm{~V}$ or cannot less than $187 \mathrm{~V}$.

Nevertheless, the experimental results have some observations. Firstly, under voltage of off-grid voltage at $V_{P C C}$ was happen before $\triangle P / P$ into positive which it showed in row 4 of Table I by $P_{\text {load }}=900 \mathrm{~W}, P=1,000 \mathrm{~W}$ and $\Delta P / P=-10$, $V_{P C C}$ before islanding condition occurs $=229.8 \mathrm{~V}$ while $V_{P C C}$ after islanding condition occurs $=191.0 \mathrm{~V}$. Second, the worst case for islanding detection when the active power matched between the load and the DG output $\left(P_{\text {load }}=P\right)$ which on-grid voltage at $V_{P C C}$ should be similar off-grid voltage at $V_{P C C}$ but the experimental results shown that $V_{P C C}$ between on-grid voltage and off-grid voltage was not similar. From Table I shown that $V_{P C C}$ before and after islanding condition most similar was $P_{\text {load }}=800 \mathrm{~W}, P=1,000 \mathrm{~W}$ and $\Delta P / P=-20$ in row 3 , on-grid voltage at $V_{P C C}=231.6 \mathrm{~V}$ and off-grid voltage at $V_{P C C}=240.5 \mathrm{~V}$.

However, these experiments were test as a parallel RLC circuit because for most islanding detection method some type of RLC load that causes the most difficulty in detection. Therefore, investigation relationship between voltage and NDZ of OUV of local islanding detection techniques by used inverter-based DG, the NDZ of active power of inverter-based DG [7], [12] is

$$
\left(\frac{V}{V_{\max }}\right)^{2}-1 \leq \frac{\Delta P}{P} \leq\left(\frac{V}{V_{\min }}\right)^{2}-1
$$

consistent with the experimental results.

\section{2) Case of synchronous-based DG}

Experimental results in Table II shows $V_{P C C}$, before and after islanding condition is happen which they are in column 5 (on-grid voltage) and column 8 (off-grid voltage), they have uneven increment of voltage and uneven decrement of voltage, and they were not associate with changing of $\Delta P$ in Fig. 4 . The analysis is consistent with "An Investigation on the Nondetection Zones of Synchronous Distributed Generation Anti-Islanding Protection" which conclusion that "voltage thresholds define reactive power imbalance limits in the case of synchronous DG'[10]. Therefore, variation of off-grid voltage at $V_{P C C}$ was not associate with variation of active power.

\section{B. Relationship between Voltage and Reactive Power}

Experimental results in Table III shows $V_{P C C}$, they are in column 5 (on-grid voltage) and column 8 (off-grid voltage), $V_{P C C}$ increase when $\triangle Q$ increase, but off-grid voltage at $V_{P C C}$ cannot more than $110 \%$ and cannot less than $88 \%$. The results accorded with Fig. 5 nondetection zone of OUV and OUF of synchronous-based DG shown that synchronous DG should be use reactive power of NDZ, $\Delta Q=[-0.32,0.12] \mathrm{p}$. u. where 1 p. u. $=30 \mathrm{MVA}$ or $\Delta Q=[-9.6,3.6]$ MVAR [10]. Therefore, NDZ of OUV of synchronous-based DG very wide, affect off-grid voltage at $V_{P C C}$ that the $V_{P C C}$ cannot outside of normal voltage range. But, if consider off-grid voltage at $V_{P C C}$ in column 8 , they are very possible that $\Delta Q$ can more than -9.6 MVAR or $\triangle Q$ can less than 3.6 MVAR which they will affect the $V_{P C C}$ to outside of normal voltage range.

\section{CONCLUSION}

Case of inverter-based DG: variation of active power associated with variation of off-grid voltage at $V_{P C C}$ and the nondetection zone of active power of inverter-based DG is

$$
\left(\frac{V}{V_{\max }}\right)^{2}-1 \leq \frac{\Delta P}{P} \leq\left(\frac{V}{V_{\min }}\right)^{2}-1
$$

consistent with the experimental results. But the experimental results of this paper have two observations. Firstly, under voltage of off-grid voltage at $V_{P C C}$ was happen before $\triangle P / P$ into positive. Second, the worst case for islanding detection is $P_{\text {load }}=P$, on-grid voltage at $V_{P C C}$ should be similar off-grid 
voltage at $V_{P C C}$ but the experimental results shown that $V_{P C C}$ between on-grid voltage and off-grid voltage was not similar.

Case of Synchronous-based DG: variation of off-grid voltage at $V_{P C C}$ was not associate with variation of active power but variation of off-grid voltage at $V_{P C C}$ associated with variation of reactive power. Nondetection zone of OUV of synchronous-based DG are very possibility that $\Delta Q$ can more than -9.6 MVAR or $\Delta Q$ can less than 3.6 MVAR which they can affect the $V_{P C C}$ to outside of normal voltage range when islanding condition is happen.

\section{REFERENCES}

[1] A. M. Massoud, K. H. Ahmed, S. J. Finney, and B. W. Williams, "Harmonic distortion-based island detection technique for inverter-based distributed generation," IET Renewable Power Generation, vol.3, no.4, pp. 493-507, 2009.

[2] IEEE Recommended Practice for Grid Interface of Photovoltaic (PV) Systems, IEEE Std. 929, 2000.

[3] IEEE Standard for Interconnecting Distributed Resources with Electric Power Systems, IEEE Std. 1547, 2003.

[4] REN21, "Renewables 2012 global status report," Renewable Energy Policy Network for the 21st Century, 2012.

[5] P. Mahat, Z. Chen, and B. B. Jensen, "Review of islanding detection methods for distributed generation," DRPT 2008, 6-9 April 2008.

[6] B. G. Yu, M. Matsui, and G. J. Yu, "A review of current anti-islanding methods for photovoltaic power system," Solar Energy, vol. 84, issue 5 , pp.745-754, 2 March 2010.

[7] Z. H. Ye, A. Kolwalkar, Y. Zhang, P. W. Du, and R. Walling, "Evaluation of anti-islanding schemes based on nondetection zone concept," IEEE Transactions on Power Electronics, vol. 19, no.5, pp.1171-1176, September 2004.

[8] H. Wang, F. R. Liu, Y. Kang, J. Chen, and X. L. Wei, "Experimental investigation on non detection zones of active frequency drift method for anti-islanding," Annual Conference of the IEEE Industrial Electronics Society, 5-8 November 2007,

[9] H. H. Zeineldin and M. M. A. Salama, "Impact of load frequency dependence on the NDZ and performance of the SFS islanding detection method," IEEE Transactions on Power Electronics, vol. 58, no. 1, pp. 139-146, January 2011.

[10] J. C. M. Vieira, W. Freitas, W. Xu, and A. Morelato, "An investigation on the nondetection zones of synchronous distributed generation anti-islanding protection," IEEE Transactions on Power Delivery, vol. 23, no. 2, pp.593-600, April 2008.

[11] D. Velasco, C. L. Trujillo, G. Garcera, and E. Figueres, "Review of anti-islanding techniques in distributed generators," Renewable and Sustainable Energy Reviews 14, pp.1608-1614, 2010.

[12] Z. Q. Mi and F. Wang, "Power equations and non-detection zone of passive islanding detection and protection method for grid connected photovoltaic generation system," in Proc. Pacific-Asia Conference on Circuits, Communications and System, 2009, pp. 360-363.

[13] M. Valentini, S. Munk-Nielsen, F. V. Sanchez, and U. M. de Estibariz, "A new passive islanding detection method for grid-connected PV inverters," in Proc. International Symposium on Power Electronics, 2008, pp. 223-228.

[14] M. Yingram and S. Premrudeepreechacharn, "Investigation over/under-voltage protection of passive islanding detection method of distributed generations in electrical distribution systems," in Proc. International Conference on Renewable Energy Research and Applications, Nagasaki, Japan, 11-14 November 2012.

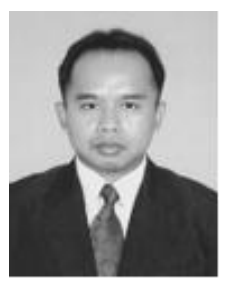

Manop Yingram was born in Nakonratchasima, Thailand on 27 September 1976. He received B.Eng. of electrical engineering in 1999 from King Mongkut's Institute of Technology Ladkrabang, Thailand and M.Eng. of electrical engineering in 2005 from Chulalongkorn University, Thailand.

Currently, he is a Ph.D. student at Chiang Mai University, Thailand.His research interests include distributed generation, photovoltaic system and islanding detection.

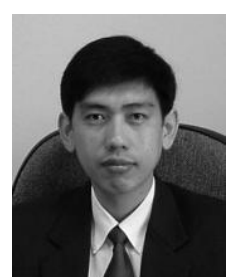

Suttichai Premrudeepreechacharn was born in Chon Buri, Thailand in 1965. He recieved B.Eng. in electrical engineering from Chiang Mai University Thailand and M.S and Ph.D. in electric power engineering from Rensselaer Polytechnic Institute, Troy, NY. He is an associate professor at Department of Electrical Engineering, Chiang Mai University, Thailand.

His research interests include power quality, high quality utility interface, photovoltaic system, power electronics and artificial intelligent applied to power system. 